\title{
Removal of heavy metals and arsenic from a co-contaminated soil by sieving combined with washing process
}

\author{
Xiaoyong Liao, ${ }^{1, *}$ You $\mathrm{Li}^{1,2}$, Xiulan $\mathrm{Yan}^{1, *}$ \\ 1. Institute of Geographic Sciences and Natural Resources Research, Chinese Academy of Science, Beijing 100101, China. \\ E-mail: Liaoxy@igsnrr.ac.cn \\ 2. University of Chinese Academy of Sciences, Beijing 100049, China
}

\section{A R T I C L E I N F O}

Article history:

Received 2 March 2015

Revised 18 May 2015

Accepted 3 June 2015

Available online 28 September 2015

Keywords:

Soil

Arsenic

Heavy metals

Separation

Washing

Remediation

\begin{abstract}
A B S T R A C T
Batch experiments were conducted with a heavy metals and arsenic co-contaminated soil from an abandoned mine to evaluate the feasibility of a remediation technology that combines sieving with soil washing. Leaching of the arsenic and heavy metals from the different particle size fractions was found to decrease in the order: $<0.1,2-0.1$, and $>2 \mathrm{~mm}$. With increased contact time, the concentration of heavy metals in the leachate was significantly decreased for small particles, probably because of adsorption by the clay soil component. For the different particle sizes, the removal efficiencies for $\mathrm{Pb}$ and $\mathrm{Cd}$ were $75 \%-87 \%$, and $61 \%-77 \%$ for $\mathrm{Zn}$ and $\mathrm{Cu}$, although the extent of removal was decreased for As and $\mathrm{Cr}$ at $<45 \%$. The highest efficiency by washing for $\mathrm{Pb}, \mathrm{Cd}, \mathrm{Zn}$, and As was from the soil particles $>2 \mathrm{~mm}$, although good metal removal efficiencies were also achieved in the small particle size fractions. Through SEM-EDS observations and correlation analysis, the leaching regularity of the heavy metals and arsenic was found to be closely related to Fe, $\mathrm{Mn}$, and Ca contents of the soil fractions. The remediation of heavy metal-contaminated soil by sieving combined with soil washing was proven to be efficient, and practical remediation parameters were also recommended.
\end{abstract}

(C) 2015 The Research Center for Eco-Environmental Sciences, Chinese Academy of Sciences. Published by Elsevier B.V.

\section{Introduction}

In recent decades, the intensification of human activities such as mining, smelting, electroplating, and coal combustion has resulted in a broad range of new environmental problems. Among these has been the widespread generation of enormous quantities of complex, heavy metal-contaminated soils, which constitute a major health challenge of global concern (Boularbaha et al., 2006). Many heavy metal-contaminated sites have been identified (Dermont et al., 2008). In the United States, heavy metals are prevalent at $77 \%$ of the Superfund sites, $72 \%$ of the Department of Defense sites, and $55 \%$ of the
Department of Energy sites, and over 50 million $\mathrm{m}^{3}$ of heavy metal-contaminated soil exist at current National Physical Laboratory sites (USEPA, 2004). In Europe, heavy metalcontaminated soils encompass several million hectares, accounting for about $37.3 \%$ of the total contaminated soil (EEA, 2014). Similar trends are also found in China, where $16.1 \%$ of the soil has been proven to be contaminated, primarily by heavy metals, and in regions characterized by heavily polluting enterprises, industrial wastelands, industrial parks, and mining areas, the contamination levels can be as high as 30\% (Ministry of Environmental Protection and the Ministry of Land, 2014).

\footnotetext{
* Corresponding author. E-mail: Yanxl@igsnrr.ac.cn (Xiulan Yan).
} 
The mobility and bio-availability of metals are significantly affected by the particle's size and composition of the soil. Fine soil fractions can adsorb more contaminants than coarse sand because of their larger specific surface areas. In general, elemental adsorption (particularly heavy metals) increases with decreasing aggregate size (Zhang et al., 2003). Anderson et al. (1999) pointed out that contaminants were concentrated in the finer ( $0.05 \mathrm{~mm}$ or less) silt and clay fractions. In addition, metal accumulation in the clay fraction is attributed to the presence of clay, organic matter, minerals, and Fe/Mn oxides in the micro-aggregates, which act as delivery vehicles for metals (Rodriguez-Rubio et al., 2003; Quenea et al., 2009). As a result, heavy metals and arsenic in clays are difficult to remove due to their strong adsorption. Cheng et al. (2008) indicated that the concentration of $\mathrm{Cu}$ in clays was as high as $670.6 \mathrm{mg} / \mathrm{kg}, 4.77$ times the concentration achieved in gravel. Gong et al. (2013) drew a similar conclusion in a soil survey in Hainan, wherein the smallest fraction $(<0.053 \mathrm{~mm})$ had the highest heavy metal concentrations.

Soil washing is one of the few treatment alternatives for the elimination of heavy metals from contaminated soils, which can be applied to pilot/full-scale field remediation (Dermont et al., 2008). The advantages of the technology are: high adaptability, a wide range for effective concentration of the contaminants, simple operation, strong regulation, short repair cycle period, lower cost, wide applicability, and huge practical value. Juwarkar et al. (2007) used 0.1 mol rhamnolipids to wash Cd-contaminated soil and obtained 91\% Cd removal at $\mathrm{pH}=10$. Torres et al. (2012) demonstrated that $\mathrm{Cd}, \mathrm{Zn}$, and $\mathrm{Cu}$ could be washed with efficiencies up to $85.9 \%, 85.4 \%$, and $81.5 \%$, respectively. Maity et al. (2013) proved that soil washing can achieve high efficiencies, with the removal of $98 \% \mathrm{~Pb}, 95 \% \mathrm{Cu}$, and $56 \% \mathrm{Zn}$.

Physical separation technologies are primarily applied in the mining and mineral processing industries to separate particulate forms of metals. These technologies include sieving, centrifugation, flocculation, hydrocyclone classification, magnetic separation, and flotation. As these technologies concentrate contaminants into smaller volumes, they have been applied in the field of soil remediation in recent years (Dermont et al., 2010; FRTR, 2007). Lin et al. (2001) removed $84 \%-88 \% \mathrm{~Pb}$ from soil by jigging and density separation, and achieved the efficient removal of $\mathrm{Pb}$ by soil washing. Reynier et al. (2013) adopted soil washing combined with flotation to eliminate heavy metals in four soils, and removal efficiencies of $82 \%-93 \%$, $30 \%-80 \%$, and $79 \%-90 \%$ were obtained for As, Cr, and $\mathrm{Cu}$, respectively.

Previous studies have shown that physical separation and soil washing can both result in the effective removal of heavy metals from soil, and even the combined technology has been attempted to remediate heavy metal-contaminated soil. Considering that soil washing is insensitive to the type of contaminant and suitable for sandy soils (Impellitteri et al., 2002), and that separation technology can reduce the volume of waste (Anderson et al., 1999), we plan to use sieving combined with soil washing to treat heavy metal-contaminated soil. The objectives of the research are to: (1) discover the occurrence, distribution characteristics, and influence of heavy metals in soil particles; (2) evaluate the removal efficiency and potential volume reduction of contaminants in the soil fractions; (3) probe the mechanism of heavy metal adherence to soil particles during the process of soil washing.

\section{Materials and methods}

\subsection{Soil samples and main physicochemical properties}

Soil sample was collected from the $0-50 \mathrm{~cm}$ surface layer of a metallurgical industry disposal site (E1130.'24"; N27 $52^{\prime} 38^{\prime \prime}$ ) located in Hunan Province, China. The sample was air-dried and homogenized at room temperature in the laboratory, and the coarse debris and visible plant materials were removed before further processing. The primary physical and chemical properties of the soil were as follows: $\mathrm{pH}$ 6.65; organic matter, $66.9 \mathrm{~g} / \mathrm{kg}$; total nitrogen, $0.13 \%$; total phosphorus, $0.11 \%$; Fe, $3.47 \%$; $\mathrm{Ca}, 5.42 \mathrm{mg} / \mathrm{kg}$; and cation exchange capacity (CEC), $15.7 \mathrm{cmol} / \mathrm{kg}$.

\subsection{Soil particle separation and metals distribution according to particle size}

For the separation procedure, the air-dried sample (250 g) was weighed and dry-sieved. The soil was subjected to $3 \times 10 \mathrm{~min}$ automatic shaking in a series of graded sieves positioned in a vibrating screen instrument (ZBSX-92A, Lei Yun Test Equipment Manufacturing Co., Ltd., China). The sieved material was divided into six graduated fraction sizes, > 2, 2-1, 1-0.25, 0.25$0.1,0.1-0.053$, and $<0.053 \mathrm{~mm}$, which corresponded to $14.63 \%$, $12.33 \%, 32.05 \%, 17.62 \%, 15.07 \%$, and $8.30 \%$ of the total original sample. The distribution of the soil was determined by the weight of each size after sieving. The sample was classified as a sandy soil according to the particle size definition by the American Society for Testing and Materials (Fig. 1).

The concentrations of trace elements (including heavy metals, Ca, and S) were analyzed by inductively coupled plasma-optical emission spectrometry (ICP-OES, Perkin-Elmer Optima 5300DV) after complete sample (0.05 g) decomposition by mixed acid digestion $\left(\mathrm{HF}-\mathrm{HNO}_{3}-\mathrm{HClO}_{4}\right.$ ) (a modification of the GB-T 17141-1997 method, NSPRC (National Specifications of the People's Republic of China), 1997). Two reference standard soils

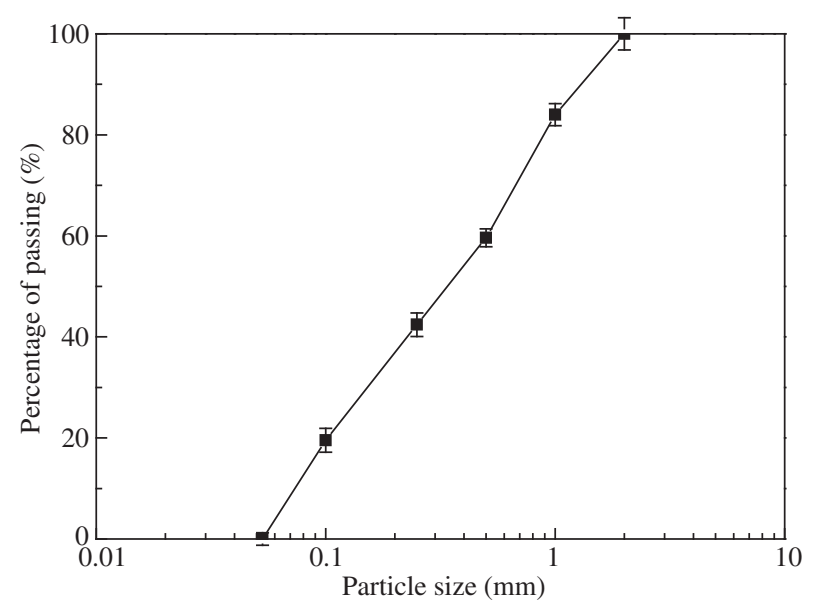

Fig. 1 - Particle-size distribution in the bulk soil sample. 
and reagent blanks were used as quality control samples to validate the accuracy and performance of the equipment during the analytical procedures. The relative standard deviations $(n=3)$ of duplicate and blank samples were less than $10 \%$ and $5 \%$, respectively.

\subsection{Sample prescreening for soil washing}

A pilot study confirmed that a mixture of $1.0 \%$ rhamnolipids in $2.0 \mathrm{~mol} / \mathrm{L} \mathrm{HCl}$ was suitable for treating the contaminated soil. Thus, batch experiments were run with the mixed solution as the flushing solution. The handling process is depicted in Fig. 2. Leaching experiments using different particle-size fractions were conducted in triplicate. The washing process was performed with $100 \mathrm{~g}$ of each soil fraction mixed with $1000 \mathrm{~mL}$ washing solution in a $2 \mathrm{~L}$ plastic bottle. The bottles were mixed in a rotary agitator (TCLP-12A, Bo Ke Test Equipment Institute, China) at $30 \mathrm{r} / \mathrm{min}$ for $2 \mathrm{hr}$; then, the supernatant was separated from the slurry by centrifugation at $3000 \mathrm{r} / \mathrm{min}$ for $15 \mathrm{~min}$. The recovered solution was filtered through a $0.45 \mu \mathrm{m}$ membrane before further measurement. The moisture in the soil separated from the slurry was removed with a vacuum freeze dryer (LGJ-10D, Four-Ring Science Instrument Plant, Beijing, Co.). Then, all the samples were well ground and digested. The washing supernatants and the digested soil samples were evaluated by ICP-OES for heavy metal content.

\subsection{SEM-EDS analysis of the soil samples}

The particles in the freeze-dried samples recovered after the soil washing experiments were also characterized by scanning electron microscopy (SEM, S4800, Hitachi, Japan) coupled with energy dispersive spectroscopy (EDS) analysis, to determine their chemical compositions and mineralogical characteristics (size, shape, and associated, enclosed, or liberated nature of the metal-bearing phase). The selected area for soil mapping $(10 \mu \mathrm{m})$ was rigorously kept the same for all samples.

\section{Results and analysis}

\subsection{Heavy metal enrichment and particle size distribution}

The distribution of heavy metals according to the six particle sizes is given in Table 1. The concentrations of $\mathrm{Pb}, \mathrm{Cd}$, and $\mathrm{Zn}$ in the soil increase with decreasing particle size, with the highest levels observed in the $<0.053 \mathrm{~mm}$ fraction. As the particle size decreases, the concentrations of $\mathrm{As}, \mathrm{Cu}$, and $\mathrm{Cr}$ decrease at first and then subsequently increase. The lowest concentrations of all the metals were present in the $1-0.1 \mathrm{~mm}$ particles.

To estimate the contribution of different particle-size fractions to the total contents of contaminants in the original soil, mass loadings were calculated, as shown in Fig. 3. The 1$0.25 \mathrm{~mm}$ particle had the largest mass loadings of metals, with total contents of $32.5 \% \mathrm{~Pb}, 30.6 \% \mathrm{Cd}, 30.7 \% \mathrm{Zn}, 29.6 \%$ As, $27.5 \% \mathrm{Cu}$, and $28.0 \% \mathrm{Cr}$. The second largest mass loadings of $\mathrm{As}, \mathrm{Cu}$, and $\mathrm{Cr}$ were found in the coarse aggregates $(>2 \mathrm{~mm})$, although smaller particle fractions $(0.25-0.1$ and $0.1-0.053 \mathrm{~mm})$ also contributed large mass loadings. The $<0.053 \mathrm{~mm}$ fraction comprised the smallest percentage of the total soil, resulting in a low mass loading.

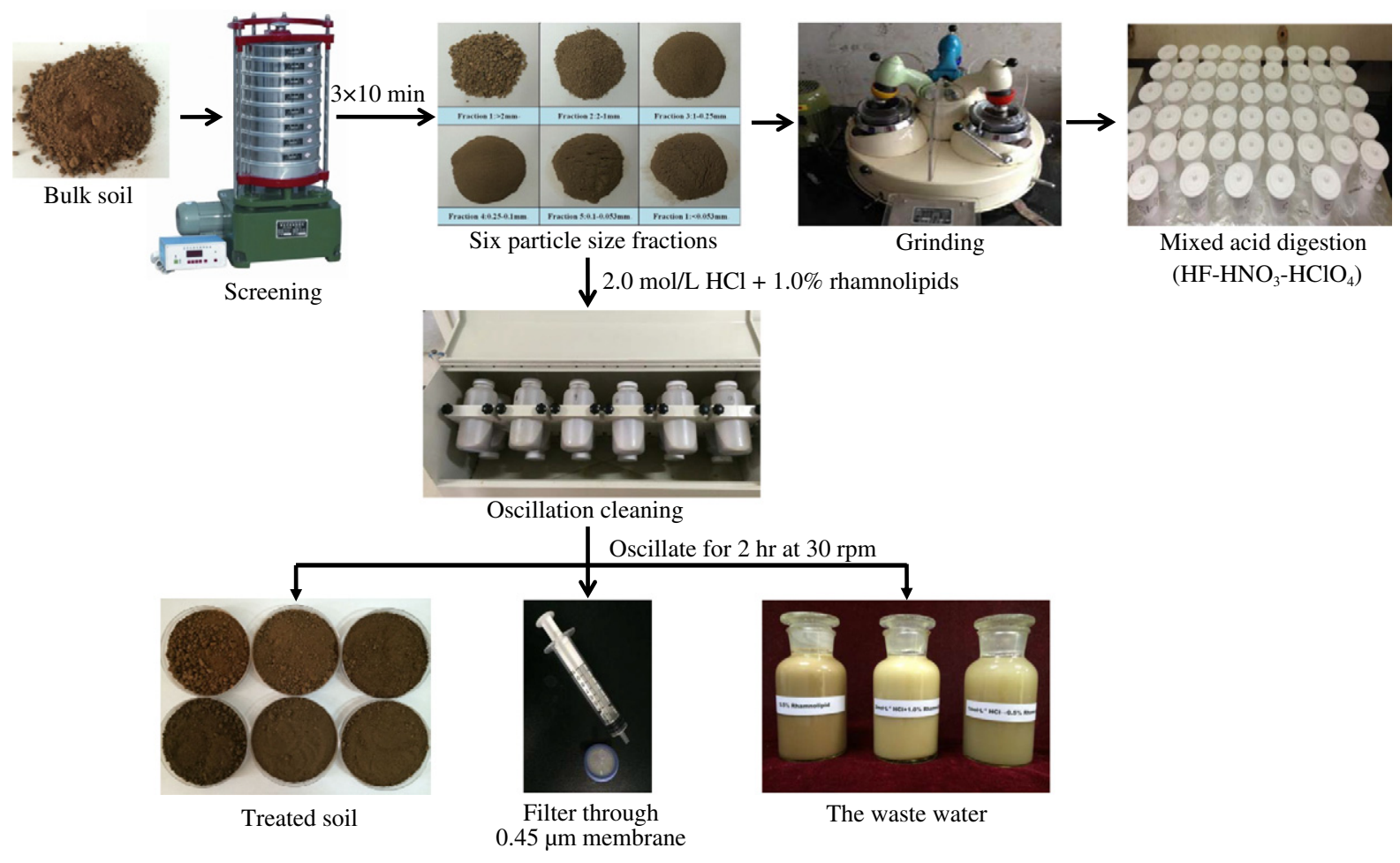

Fig. 2 - Experimental flow diagram. 
Table 1 - Concentration distribution of heavy metals and arsenic according to particle size (mg/kg).

\begin{tabular}{lrrrrrrr} 
& Origin soil & $>2 \mathrm{~mm}$ & $2-1 \mathrm{~mm}$ & $1-0.25 \mathrm{~mm}$ & $0.25-0.1 \mathrm{~mm}$ & $0.1-0.053 \mathrm{~mm}$ & $<0.053 \mathrm{~mm}$ \\
\hline $\mathrm{Pb}$ & 3623.79 & 2514.40 & 3247.00 & 3761.68 & 3604.63 & 4378.40 & 290.43 \\
$\mathrm{Cd}$ & 234.58 & 127.04 & 217.83 & 222.42 & 249.27 & 8355.64 \\
$\mathrm{Zn}$ & 9091.50 & 6587.70 & 9282.19 & 8581.77 & 271.77 & 10277.25 & 11848.38 \\
$\mathrm{Cr}$ & 249.75 & 393.96 & 361.68 & 267.80 & 271.63 & 302.54 \\
$\mathrm{As}$ & 555.79 & 520.54 & 448.39 & 414.13 & 398.03 & 452.67 & 546.66 \\
$\mathrm{Cu}$ & 1220.65 & 1141.93 & 697.26 & 621.42 & 591.36 & 762.60 \\
\hline
\end{tabular}

\subsection{Leaching dynamics of the metals by particle-size fraction}

Similar trends for the leaching dynamics of $\mathrm{Pb}, \mathrm{Cd}, \mathrm{Zn}$, and $\mathrm{Cu}$ for each particle size were found in the washing process (Fig. 4). The fraction ( $>2 \mathrm{~mm}$ ) had the lowest concentration of metals in the effluent; the concentration increased over the first $100 \mathrm{~min}$ and then began to decline. The three particle-size fractions in the 2-0.1 mm range had minimal $\mathrm{Pb}, \mathrm{Cd}, \mathrm{Zn}$, and $\mathrm{Cu}$ concentration differences, and their variations with time were small, in the ranges 300.3-395.4 (Pb), 17.6-23.6 (Cd), 535.4-636.6 (Zn), and 42.5-58.1 (Cu) mg/L, respectively. After $40 \mathrm{~min}$ soil washing, the $<0.053 \mathrm{~mm}$ fraction afforded the maximum total heavy metal leachate, with concentrations of $\mathrm{Pb}, \mathrm{Cd}, \mathrm{Zn}$, and $\mathrm{Cu}$ of 693.5, 35.9, 803.5 , and $74.5 \mathrm{mg} / \mathrm{L}$, respectively. The second highest level was observed in the $0.1-0.053 \mathrm{~mm}$ fraction. During the $40-50 \mathrm{~min}$ time period, a dramatic fall in the concentrations of the metals was observed, which began to level off at $60 \mathrm{~min}$ and achieved a concentration similar to the $2-0.1 \mathrm{~mm}$ fraction. The $\mathrm{Cr}$ concentration in the solution was not significantly different from the behaviors of the aforementioned metals except for the $<0.1 \mathrm{~mm}$ fractions.

Being different from the other metals, the concentration of As for the various particle sizes remained within a small range as time elapsed. The fraction $(<0.053 \mathrm{~mm})$ was consistently superior with a concentration on the scale of 33.9$39.9 \mathrm{mg} / \mathrm{L}$, and was closely followed by the $0.1-0.053 \mathrm{~mm}$ fraction with the range $29.9-34.4 \mathrm{mg} / \mathrm{L}$. There were minor differences among the As concentrations in the $2-0.1 \mathrm{~mm}$ fractions, which had an average level of $10.8 \mathrm{mg} / \mathrm{L}$. The minimum concentration was observed in the fraction of $>2 \mathrm{~mm}$ at $3.9 \mathrm{mg} / \mathrm{L}$.

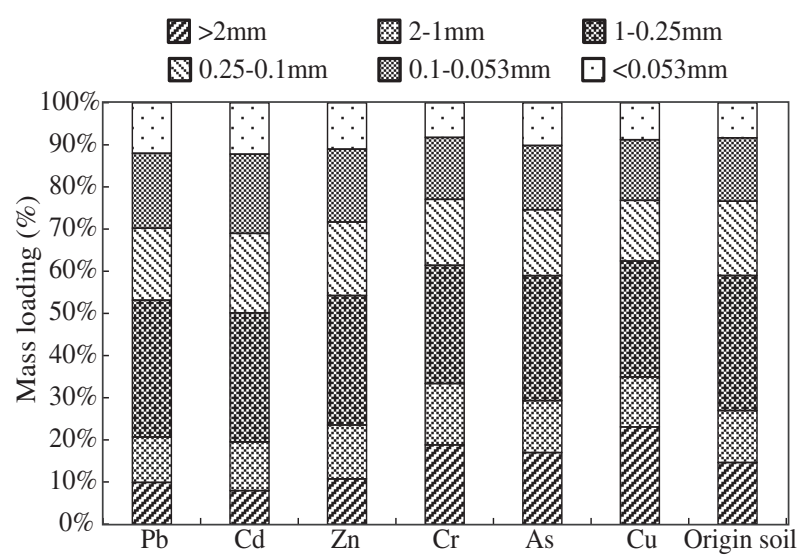

Fig. 3 - Heavy metal mass loadings for the six particle-size fractions.

\subsection{Metal leaching efficiency in different size particulates}

According to the results presented in Table 2, the removal efficiencies of the different particle sizes in decreasing order of: $\mathrm{Pb}, \mathrm{Cd}>\mathrm{Zn}, \mathrm{Cu}>\mathrm{As}$, Cr. There was a distinct difference among heavy metal removal efficiencies from the soil depending on soil particle diameters. A larger particle size did not necessarily result in greater removal efficiency for arsenic and heavy metals. The highest removal efficiencies by washing for $\mathrm{Pb}, \mathrm{Cd}, \mathrm{Zn}$, and As were obtained in the fraction of $>2 \mathrm{~mm}$. However, these results differ from prior studies, because the small particle size fractions can also achieve high heavy metal removal efficiencies. Compared with the original efficiency, the equivalent efficiencies for $\mathrm{Pb}, \mathrm{Cd}$, and $\mathrm{Zn}$ had been enhanced, whereas the equivalent efficiencies for As and $\mathrm{Cu}$ were lower.

\subsection{SEM-EDS analysis and mobilization correlation}

The composition, surface topography, and element distribution of the soil samples were analyzed by SEM-EDS (Fig. 5). Using these results and correlation analysis (Table 3), we studied the relationship between the heavy metal distribution and $\mathrm{Ca}, \mathrm{Mg}, \mathrm{Al}, \mathrm{S}, \mathrm{P}, \mathrm{Fe}$, and $\mathrm{Mn}$ contents in the soil. In this study, we found that the heavy metal distribution was related to $\mathrm{Fe}, \mathrm{Mn}$, and $\mathrm{Ca}$ contents, but independent of the $\mathrm{Mg}, \mathrm{Al}, \mathrm{S}$, and $\mathrm{P}$ distribution (data not shown).

Aggregates are formed during treatment and appear on the surfaces of the soil particles. Comparing the images and peaks both before and after processing, we found that arsenate and zinc slags can be found in almost every fraction before treatment, whereas the arsenic slag disappears after processing and the zinc is reduced. At the same time, the content of Fe in the particles of $>2$ and $0.1-0.053 \mathrm{~mm}$ declined, whereas the concentration of Ca tended to increase overall, with the exception of the grain size of $0.1-0.053 \mathrm{~mm}$. $\mathrm{Mn}$ was detected only in the $1-0.25$ and $0.1-0.053 \mathrm{~mm}$ fractions and obtained a decreased concentration after treatment. The As content exhibited a remarkable positive linear correlation $(p<0.01)$ with $\mathrm{Fe}$ both before and after treatment, whereas in the process of soil washing, it was significantly and positively correlated with Ca. Before processing, Zn was significantly and positively correlated with $\mathrm{Ca}$, although it became significantly and positively correlated with Fe after processing. For the other elements, there were highly significant correlations between $\mathrm{Cu}$ and $\mathrm{Fe}, \mathrm{Cd}$ and $\mathrm{Ca}$, and $\mathrm{Cd}$ and $\mathrm{Mn}$ before treatment, but less significant correlations occurred between $\mathrm{Cu}$ and $\mathrm{Ca}, \mathrm{Cu}$ and $\mathrm{Mn}$, and $\mathrm{Cd}$ and $\mathrm{Fe}$ after treatment. 

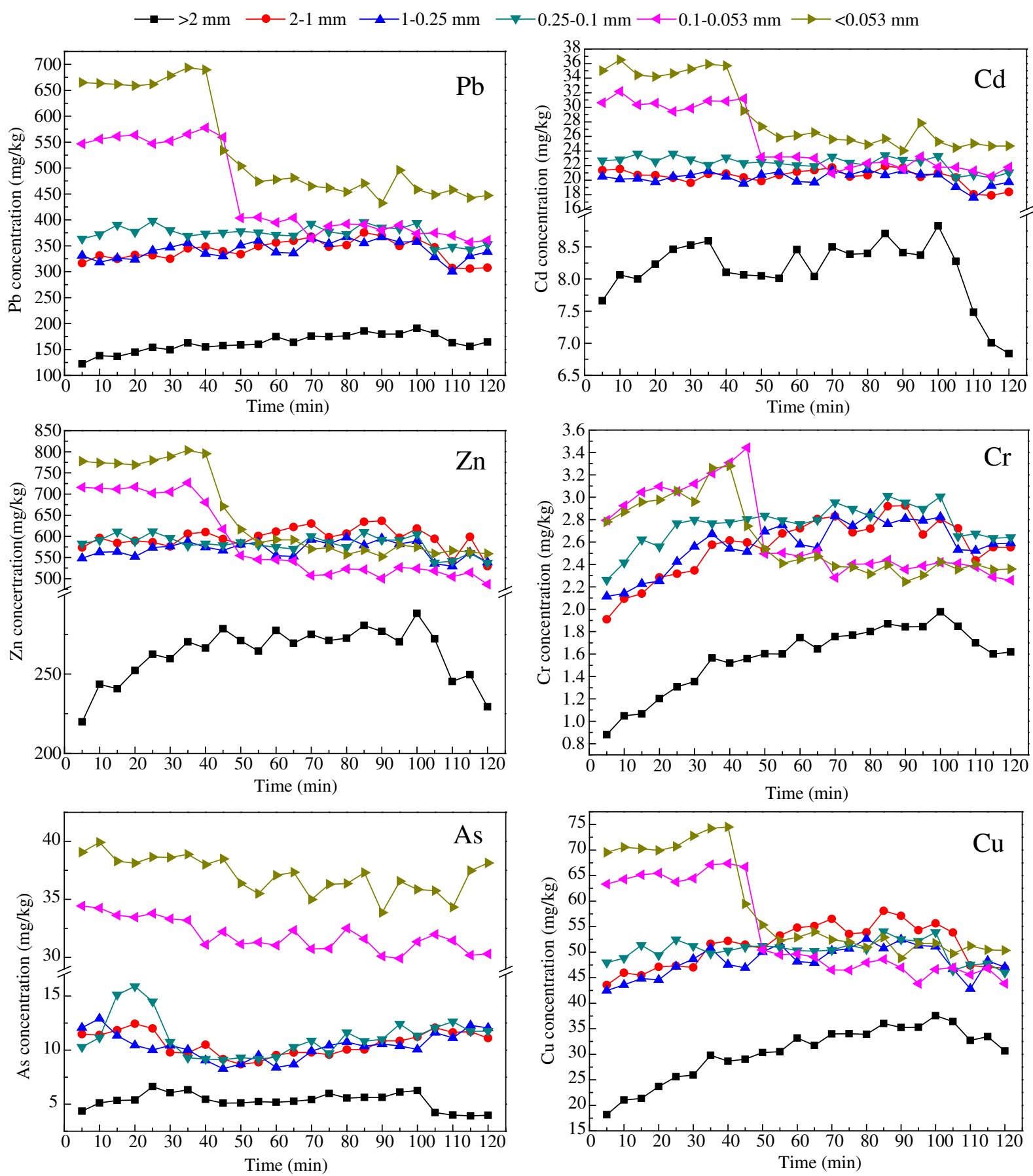

Fig. 4 - Average of $\mathrm{Pb}, \mathrm{Cd}, \mathrm{Zn}, \mathrm{Cr}, \mathrm{As}$, Cu concentrations in the effluents from the batch tests with $1 \mathrm{~mol} / \mathrm{L} \mathrm{HCl}$ and $0.5 \%$ rhamnolipids.

\section{Discussion}

3.1. Evaluation of soil washing combined with sieving technology

Soil washing combined with sieving is an effective method for removing heavy metals in soil. The maximum removal efficiencies for $\mathrm{Pb}, \mathrm{Cd}, \mathrm{Zn}$, and As were obtained for the grain sizes $>2 \mathrm{~mm}$, although the small size grains also exhibited very high levels of efficiency. The grains $<0.053 \mathrm{~mm}$ removed larger amounts of $\mathrm{Pb}, \mathrm{Cd}$, and $\mathrm{Zn}$, and produced higher leaching losses of As and $\mathrm{Cu}$. Previous studies indicated that soil washing is suitable for porous sandy soils with high permeability. Once the soil has a high content of organic matter or clays (>30\%), soil washing is considered ineffective for heavy metal remediation. Kuhlman and Greenfield (1999) showed that soil particles finer than $0.02 \mathrm{~mm}$ can also be washed, but only if the contaminants can be solubilized in water or a suitable extractant, or separated by flotation. 

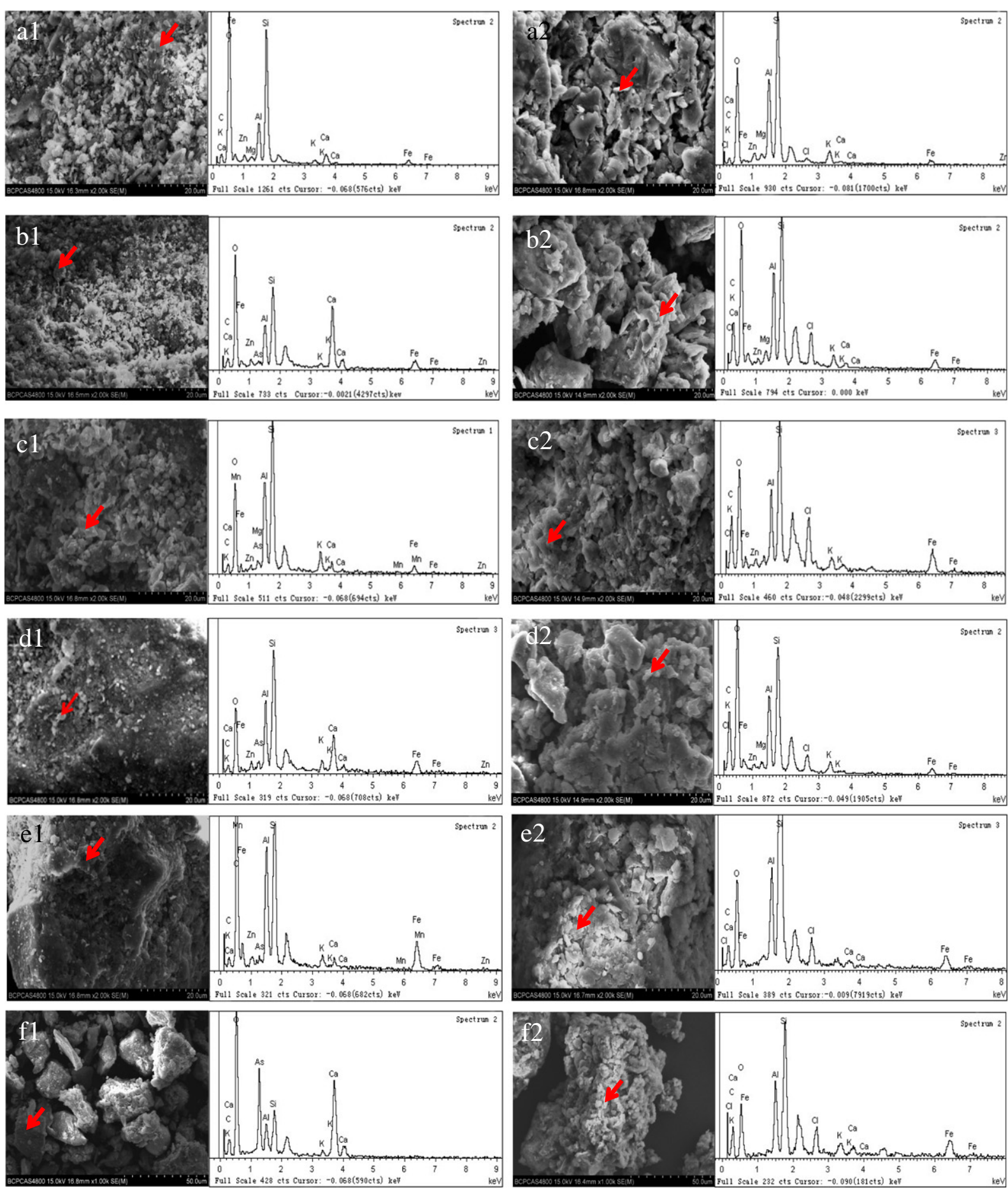

Fig. 5 - SEM micrographs and EDS chromatograms of the six particle-size fractions before and after treatment. (a) >2 mm; (b) 1-2 mm; (c) 0.25-1 mm; (d) 0.1-0.25 mm; (e) 0.053-0.1 mm; (f) <0.053 mm; 1: before treatment; 2: after treatment.

found that the As was strongly adsorbed on the surfaces of $\mathrm{Fe}(0)$ and $\mathrm{FeOOH}$. Moreover, the rhamnolipids, which are negatively charged, compete with arsenic anions for adsorption sites, and therefore inhibit the mobilization of arsenic (Wang and Mulligan, 2009). The smaller particle-size grains are enriched with large amounts of Fe-Mn oxides, which have specific adsorption sites for As and result in low removal efficiency. Most of the As bound to Fe is difficult to wash efficiently and this can be explained why As is less favorably transferred in the soil than the other metals.

\section{Conclusions}

The technology of sieving combined with washing for the remediation of soil co-contamination was evaluated through 
Table 3 - Correlation analysis of heavy metal over process stages.

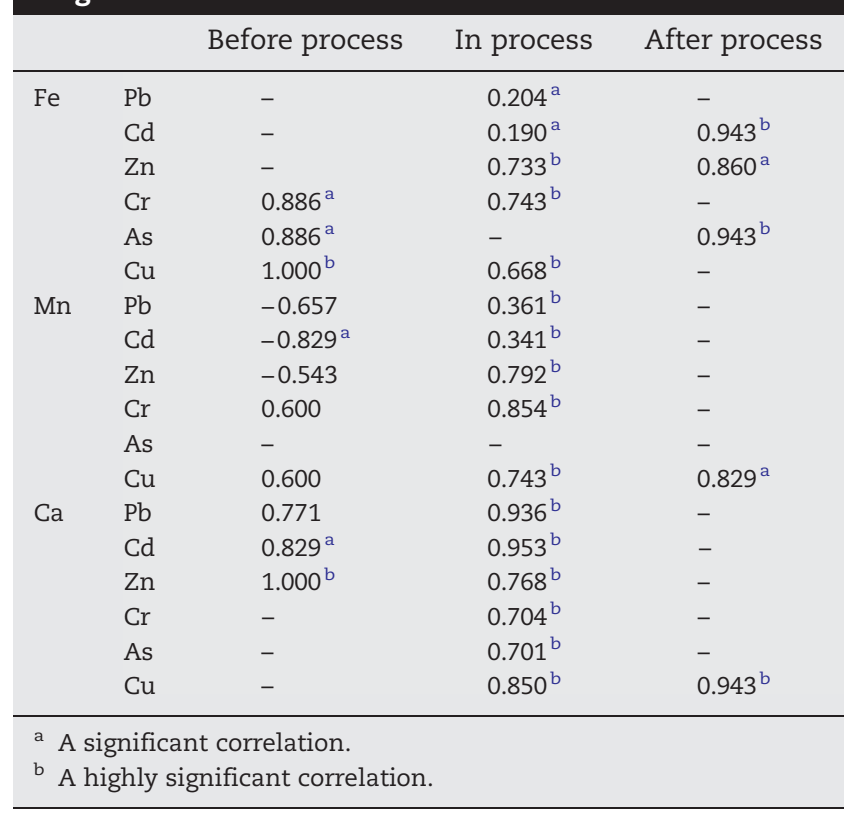

batch experiments. The approach was proven to concentrate the pollutants into smaller volumes of soil and effectively removed metals. The following conclusions were derived:

(1) The concentrations of leached metals increased with decreasing particle sizes.

(2) The dynamics of leaching were similar among $\mathrm{Pb}, \mathrm{Cd}$, $\mathrm{Zn}, \mathrm{Cr}$, and $\mathrm{Cu}$, whereas As was different, presenting a decreasing trend with time.

(3) The removal efficiency of the different particle sizes in decreasing order was $\mathrm{Pb}, \mathrm{Cd}>\mathrm{Zn}, \mathrm{Cu}>\mathrm{As}$, and $\mathrm{Cr}$.

\section{Acknowledgments}

This work was supported by the National High Technology Research and Development Program of China (863 Program) (No. 2012AA06A201) and the Science and Technology Project of Beijing (No. Z141100000914011).

\section{R E F E R E N C E S}

Anderson, R., Rasor, E., Ryn, F.V., 1999. Particle size separation via soil washing to obtain volume reduction. J. Hazard. Mater. 66 (1), 89-98.

Boularbaha, A., Schwartzb, C., Bittonc, G., Morel, J.L., 2006. Heavy metal contamination from mining sites in South Morocco: 1. Use of a biotest to assess metal toxicity of tailings and soils. Chemosphere 63 (5), 802-810.

Cheng, S.F., Chang, J.H., Huang, C.Y., 2008. Copper distribution for contaminated soils and acid washing efficiency. J. Chin. Inst. Eng. 31 (2), 231-237.

Dermont, G., Bergeron, M., Mercier, G., Richer, L.M., 2008. Soil washing for metal removal: a review of physical/chemical technologies and field applications. J. Hazard. Mater. 152, 1-31.
Dermont, G., Bergeron, M., Richer, L.M., Mercier, G., 2010. Remediation of metal-contaminated urban soil using flotation technique. Sci. Total Environ. 408, 1199-1211.

EEA, 2014. Overview of contaminants affecting soil and groundwater in Europe. http://www.eea.europa.eu/data-andmaps/figures/overview-of-contaminants-affecting-soil-andgroundwater-in-europe.

FRTR, 2007. Table 3-8 completed projects: ex situ physical/ chemical treatment for soil, sediment, sludge. http://www.frtr. gov/matrix2/section3/table3-8nfr.html.

Gong, C., Ma, L., Cheng, H., Liu, Y., Xu, D., Li, B., et al., 2013. Characterization of the particle size fraction associated heavy metals in tropical arable soils from Hainan Island, China. J. Geochem. Explor. 139, 109-114.

Impellitteri, C.A., Lu, Y., Saxe, J.K., Allen, H.E., Peijnenburg, W.J.G.M., 2002. Correlation of the partitioning of dissolved organic matter fractions with the desorption of $\mathrm{Cd}, \mathrm{Cu}, \mathrm{Ni}, \mathrm{Pb}$ and $\mathrm{Zn}$ from 18 Dutch soils. Environ. Int. 28, 401-410.

Juwarkar, A.A., Nair, A., Dubey, K.V., Singh, S.K., Devotta, S., 2007. Biosurfactant technology for remediation of cadmium and lead contaminated soils. Chemosphere 68 (10), 1996-2002.

Kuhlman, M., Greenfield, T., 1999. Simplified soil washing processes for a variety of soils. J. Hazard. Mater. 66, 31-45.

Kumpiene, J., Lagerkvist, A., Maurice, C., 2008. Stabilization of As, $\mathrm{Cr}, \mathrm{Cu}, \mathrm{Pb}$ and $\mathrm{Zn}$ in soil using amendments-a review. Waste Manag. 28, 215-225.

Lee, M., Paik, I.S., Do, W., Kim, I., Lee, Y., Lee, S., 2007. Soil washing of As-contaminated stream sediments in the vicinity of an abandoned mine in Korea. Environ. Geochem. Health 29 (4), 319-329.

Lin, H.K., Man, X.D., Walsh, D.E., 2001. Lead removal via soil washing and leaching. J. Miner. Met. Mater. Soc. 53, 22-25.

Maity, J.P., Huang, Y.M., Hsu, C.M., Wu, C.I., Chen, C.C., Li, C.Y., et al., 2013. Removal of $\mathrm{Cu}, \mathrm{Pb}$ and $\mathrm{Zn}$ by foam fractionation and a soil washing process from contaminated industrial soils using soapberry-derived saponin: a comparative effectiveness assessment. Chemosphere 10 (92), 1286-1293.

Manning, B.A., Fendorf, S.E., Bostick, B., Suarez, D., 2002. Arsenic(III) oxidation and Arsenic(V) adsorption reactions on synthetic birnessite. Environ. Sci. Technol. 36, 976-981.

Matera, V., Hecho, I.L., Laboudigue, A., Thomas, P., Tellier, S., Astruc, M., 2003. A methodological approach for the identification of arsenic bearing phases in polluted soils. Environ. Pollut. 126, 51-64.

Ministry of Environmental Protection and the Ministry of Land, 2014. National Survey Bulletin Soil Pollution, China. http:// www.mep.gov.cn/gkml/hbb/qt/201404/t20140417_270670.htm.

Miretzky, P., Cirelli, A.F., 2010. Remediation of arseniccontaminated soils by iron amendments: a review. Crit. Rev. Environ. Sci. Technol. 40, 93-115.

Mukhopadhyay, S., Hashim, M.A., Sahu, J.N., Yusoff, I., Gupta, B.S., 2013. Comparison of a plant based natural surfactant with SDS for washing of $\mathrm{As}(\mathrm{V})$ from Fe rich soil. J. Environ. Sci. 25, 2247-2256.

Mulligan, C.N., Yong, R.N., Gibbs, B.F., 2001. Heavy metal removal from sediments by biosurfactants. J. Hazard. Mater. 85, 111-125.

NSPRC (National Specifications of the People's Republic of China), 1997. Soil Quality-Determination of Lead, Cadmium-Graphite Furnace Atomic Absorption Spectrophotometry. GB-T 17141-1997 (in Chinese).

Ouvrard, S., Dedonato, P., Simonnot, M., Begin, S., Ghanbaja, J., Alnot, M., et al., 2005. Natural manganese oxide: combined analytical approach for solid characterization and arsenic retention. Geochim. Cosmochim. Acta 69 (11), 2715-2724.

Qian, J., Wang, Z.J., Tu, Q., Shana, X.Q., 1996. Distribution and plant availability of heavy metals in different particle-size fractions of soil. Sci. Total Environ. 187 (2), 131-141. 
Quenea, K., Lamy, I., Winterton, P., Bermond, A., Dumat, C., 2009. Interactions between metals and soil organic matter in various particle size fractions of soil contaminated with waste water. Geoderma 149 (3), 217-223.

Reynier, N., Blais, J.F., Mercier, G., Besner, S., 2013. Treatment of arsenic-, chromium-, copper and pentachlorophenol-polluted soil using flotation. Water Air Soil Pollut. 224, 1514-1526.

Rodriguez-Rubio, P., Morillo, E., Madrid, L., Undabeytia, T., Maqueda, C., 2003. Retention of copper by a calcareous soil and its textural fractions: influence of amendment with two agroindustrial residues. Eur. J. Soil Sci. 54 (2), 401-409.

Sierra, C., Blanco, D.M., Blanco, J.A., Gallegoa, J.R., 2014.

Optimisation of magnetic separation: a case study for soil washing at a heavy metals polluted site. Chemosphere 107, 290-296.

Torres, L.G., Lopez, R.B., Beltran, M., 2012. Removal of As, Cd, Cu, $\mathrm{Ni}, \mathrm{Pb}$, and $\mathrm{Zn}$ from a highly contaminated industrial soil using surfactant enhanced soil washing. Phys. Chem. Earth 37, 30-36.
USEPA, 2004. Cleaning up the nation's waste sites: markets and technology trends. EPA 542-R-04-015 4th ed. Office of Solid Waste and Emergency Response, Washington, DC.

Wang, S., Mulligan, C.N., 2004. Rhamnolipid foam enhanced remediation of cadmium and nickel contaminated soil. Water Air Soil Pollut. 157, 315-330.

Wang, S., Mulligan, C.N., 2009. Rhamnolipid biosurfactantenhanced soil flushing for the removal of arsenic and heavy metals from mine tailings. Process Biochem. 44, 296-301.

Yuan, C., Chiang, T.S., 2007. The mechanisms of arsenic removal from soil by electrokinetic process coupled with iron permeable reaction barrier. Chemosphere 67, 1533-1542.

Zhang, M., He, Z., Calvert, D., Stoffella, P., Yang, X., Li, Y., 2003. Phosphorus and heavy metal attachment and release in sandy soil aggregate fractions. Soil Sci. Soc. Am. J. 67 (4), 1158-1167. 